\title{
Falocentrismo e heteronormatividade na tradución: de como varren as mulleres e as lesbianas da historia cun golpe de pence
}

\author{
Robert Neal Baxter \\ Universidade de Vigo
}

\author{
Traducido por \\ Iván Fontão Bestilheiro \\ Iago González Pascual
}

\begin{abstract}
Resumo:
Este artigo interdisciplinar parte de estudos baseados na tradución como ferramenta metodolóxica para indagar na maneira en que as/os tradutoras/es entendidas/os como usuarias/os arquetípicas/os da linguaxe poden proxectar mediante o uso inapropiado da linguaxe normas heterosexistas socialmente dominantes sob o pretexto de seren de interpretacións neutrais. Máis especificamente, aborda a cuestión das normas androcéntricas que rexen a linguaxe e que levan, por forza, a estereótipos sexuais e de xénero no xeral e ao heterosexismo en particular. Alén de analizar instancias nas que a tradución ten sido utilizada de maneira consciente para censurar papeis de xénero que se sitúen fóra das normas falocéntricas, e máis especialmente a sexualidade feminina, dentro do cadro teórico de xénero latente (covert) face a xénero patente (overt) asociado cos conceptos relacionados de denotación e connotación semántica, o artigo afunda na maneira en que poden ser útiles exercicios baseados na tradución construídos ao redor de pares de linguas que non marcan o xénero gramaticalmente con outras que si o marcan de maneira obrigatoria para así tornar visíbeis calquera preconceptos até inclusive inconscientes por parte das/os propias/os tradutora/es. A un nivel xa máis amplo, o artigo tenta desvelar as potenciais implicacións que leva parello a tradución como un medio que serve para censurar non só sexualidades socialmente marxinalizadas senón tamén para proxectar determinadas visións ideoloxizadas do que se entende como normal ou non, o que leva á necesidade de as tradutoras e os tradutores se tornaren máis conscientes e responsábeis a respecto das súas propias expectativas social e culturalmente condicionadas.
\end{abstract}

\section{Palabras chave:}

Androcentrismo e heteronormatividade, estudos da tradución, estudos queer, mulleres e lesbiana, xénero latente e patente, xénero gramatical/social na linguaxe, denotación e connotación.

\begin{abstract}
:
This transdisciplinary paper uses translation-based studies as a methodological tool for exploring the way translators seen as archetypical language users can and do project socially dominant heterosexist norms masquerading as neutral interpretations via inappropriate language usage. The article specifically deals with andocentric language conventions which of necessity lead to gender and sexual stereotyping in general and heterosexism in particular. As well as analysing the way translation has been used quite consciously as a means of censu-
\end{abstract}


ring non-malestream gender roles, especially female sexuality, within the theoretical framework of covert versus overt gender associated with the related concepts of semantic denotation and connotation, the article goes on to explore the way translation-based exercises using epicene and grammatical-gendered language pairs can be deployed as a way of bringing to the surface underlying preconceptions of which the translator cum language-user may not even be aware. On a broader level, the article shows that the implications that translation as a means of censuring not only socially marginalised sexualities but also as a means of projecting, wittingly or otherwise, a particular ideological world-view of what is assumed to be normal and what is not, calling for a need to heighten translator awareness and responsibility regarding their own culturally and socially constrained expectations.

Key words:

Androcentrism \& heteronormativity, translation studies, queer studies, wimyn and lesbians, covert and overt gender, grammatical vs. social gender in language, denotation and connotation.

'Outras mulleres que buscan entre os cartóns pergúntanse: onde están as mulleres?

Por que non hai biografías de mulleres? Exprimen unha xorda indignación:

sen quereren chamar a atención sobre si mais incapaces de aceptaren que non haxa mulleres entre os centos de cartóns [...]. No museo falta a historia das mulleres.

As mulleres son conceptualmente invisíbeis [...]. Necesito saber das que resistiron e das que escaparon, porque houbo algunhas. Necesito un patrimonio do lado feminino

(Dworkin 1994).

\section{Introdución}

Segundo a tan citada hipótese de Sapir-Whorf, existe unha relación directa entre a lingua e o modo en que un/ha falante percibe o mundo e interaxe con el:

Disecamos a natureza seguindo os parámetros impostos polas nosas linguas maternas. Non encontramos no mundo dos fenómenos as categorías e tipos que del isolamos porque estean a mirar os ollos de todos os observadores; ao contrario, o mundo preséntase como un fluxo caleidoscópico de impresións que debe ser organizado pola nosa mente, isto é, principalmente polos sistemas lingüísticos da nosa mente. Seccionamos a natureza, organizámola en conceptos e atribuímos significados no modo en que o facemos, en grande medida, debido ao facto de facermos parte dun acordo polo cal o organizamos así: un acordo respectado en toda a comunidade lingüística e codificado no esquema da nosa lingua... (Whorf 1964: 212-214). 
Embora as versións máis radicais do determinismo lingüístico teñan poucos adherentes, outras versións mais moderadas, segundo as cales a lingua inflúe no pensamento e vice-versa, son xeralmente aceptadas como factos. Dito doutro xeito, a lingua que usamos, e especialmente o modo en que a usamos, non son necesariamente triviais ou accidentais, mais poden tamén exprimir percepcións e expectativas culturais e ideolóxicas subxacentes. Estas nin só representan como o mundo é na realidade, mais tamén, e o que é mais importante, como pensamos que debería ser.

Nunha perspectiva máis social, a implicación disto é que a lingua en xeral e o uso lingüístico en particular reflicten as percepcións androdominantes e heteronormativas:

Os homes non forneceron significados que debilitasen o seu poder, minguasen o seu prestixio ou deteriorasen a súa imaxe. De forma intencional ou non, elaboraron unha regra semántica que os sitúa como elemento central e positivo, como a norma. $\mathrm{E}$ foi a partir deste punto de referencia que clasificaron o mundo e construíron un sistema simbólico que representa a orde patriarcal (Spender 1985: 58).

Como fenómeno lingüístico fundamente enraizado en percepcións sociais e culturais, a tradución non pode senón reflectir os mesmos preconceptos subxacentes relativos ás expectativas de xénero e de sexualidade, centradas na norma de comportamento dominante, tal como é codificada, propositadamente ou non, nos textos traducidos a través do prisma dos filtros ideolóxicos socialmente condicionados do/a tradutor/a.

En suma, se a sociedade é (hetero)sexista, do que non cabe dúbida, sería no mellor dos casos inxenuo e no peor cínico presupor ou afirmar que a tradución, como actividade realizada por individuos que traballan con linguas que están por súa vez inevitabelmente condicionadas por factores e expectativas socioculturais, podería ser doutra maneira.

No entanto, o modo en que usamos a lingua nin só afecta o modo en que percibimos a realidade, mais pode mesmo axir sobre ela e afectala na forma dos chamados "actos de fala performativos". Estes poden ser descritos como actos de fala que realizan a acción que describen as elocucións. Por exemplo, dicindo "Eu declárovos marido e muller", un sacerdote muda realmente o status persoal, social e legal das persoas a quen a proclamación se refire.

Autores como Sedgwick (1995) que teñen investigado a relación existente entre o uso da lingua e a realidade dentro do campo académico dos Queer Studies opinan que, en contra da crenza popular, case todas as palabras, oracións è actos de fala posúen aspectos performativos. Así, oracións aparentemente non performativas 
poden ter unha natureza performativa, ao revelaren e reafirmaren suposicións subxacentes sobre o mundo que reforzan os sistemas de poder e valores dominantes e que, deste xeito, contribúen a re-/su-primir grupos marxinais e/ou marxinalizados. A marxinalidade pode ser definida, polo menos con fins prácticos, en termos negativos como os fenómenos e/ou os grupos que se sitúan alén ou na periferia do conxunto de valores androdominantes centrais dentro dun dado sistema de valores socioculturais, isto é, aquilo que está fóra ou na periferia da "norma" no sentido polisistémico do termo (Even-Zohar 1990; Toury 1981).

Nunha tentativa de estabelecermos unha diferenza entre o que é anormal por oposición ao que é considerado anómalo, é útil introducirmos unha diferenza semántica entre o termo propositadamente neutral "normatividade", que se refire a aquilo que axe de acordo cos valores centrais dun dado sistema, isto é, a "norma", para evitarmos as connotacións e os xuízos de valor asociados co termo "normalidade", co significado de "normal", isto é, que cumpre as expectativas socioculturais referidas ao comportamento e aos valores aceptábeis. Por tanto, aquí o termo "marxinal(izado)" refírese a todo fenómeno ou grupo anormal, por exemplo, non-(hetero)WASP' ${ }^{1}$, e, nun sentido largo, pode ser aplicado a conceptos tan díspares como linguas e culturas subordinadas ou subrepresentadas, así como aos intercambios desiguais e tamén ao modo en que algúns grupos sociais marxinalizados, como as mulleres, son representados.

Estas cuestións son especialmente interesantes no campo dos Estudos da Tradución, vistos como un ramo dos estudos de política sociocultural debido á súa transversalidade, isto é, a que abranxen todos os outros parámetros variábeis como a lingua, a cultura, o xénero literario, a tipoloxía textual etc.

Algunhas autoras notábeis como de Lotbinière-Harwood (1991), von Flotow (1997), Martín Ruano (2003) e Nissen $(1994,2002)$ tentaron estudar o xeito en que as mulleres, como grupo marxinal, son representadas, e todas parecen estar de acordo en que as mulleres son frecuentemente perdidas na tradución. Nun nivel práctico, tales preocupacións levaron mesmo a unha tradución da Biblia ao inglés xenericamente neutra. Foi publicada en 2005 como The Holy Bible: Today's New International Version (Zondervan Publishing) e auspiciada pola Asociación Bíblica Internacional, e xa leva varias edicións.

Tal aumento do interese neste problema pode ser con certeza atribuído, polo menos en grande medida, ao modo en que o "feminismo" foi sendo absorbido no discurso dominante na cultura occidental, especialmente na angloame-

1 N. dos T.: White Anglo-Saxon Protestant 'Branco, Anglo-Saxónico e Protestante', termo empregue na sociedade dos EUA para se denotar a cultura, os costumes e o patrimonio do grupo social dominante formado pola descendencia dos colonos británicos. 
ricana, durante as últimas décadas. A isto contribuíron políticas de "mainstreaming" como as da Unión Europea, que axudaron a tirar estas cuestións do ámbito da marxinalidade e inclúlas no discurso dominante: "Definición [de mainstreaming]: implementación da igualdade de oportunidades para as mulleres e os homes en todas as políticas e actividades comunitarias" (Comisión Europea 1995-2005).

No entanto, a pesar dos esforzos académicos concentrados na comprensión das cuestións de xénero, o problema da distinción entre a sexualidade e o xénero foi deixado á marxe. De facto, aínda que aluda a outras notábeis características socioculturais dominantes como a relixión e a cor da pel, mesmo o termo estadounidense WASP utilizado acima para identificar a sociedade androdominante da Europa Occidental e da América do Norte obvia a orientación sexual. Non porque non teña importancia, mais porque se presupón a heterosexualidade sen que sexan contempladas outras alternativas como plausíbeis ou posíbeis.

Con certeza, sería interesante estabelecerse un paralelo legal polo cal, historicamente, a cuestión das lesbianas, como subgrupo específico de mulleres, foi recoñecida e tratada na lexislación en xeral en moita menor medida, aínda que dun modo igualmente negativo, que a cuestión das relacións homosexuais masculinas, xa que na lexislación histórica se ten aludido implícita ou explicitamente á homosexualidade como un acto consentido só entre homes. Noutras palabras, a sexualidade feminina é explicitamente ignorada mesmo na lexislación que se refire á sexualidade en xeral e á homosexualidade en particular:

As prohibicións explícitas referidas ao comportamento homosexual feminino foron moito menores nas sociedades occidentais do que as referidas ao comportamento homosexual masculino. No Reino Unido o lesbianismo nunca foi ilegal, mais si a homosexualidade masculina, que foi criminalizada durante o fin do século XIX [...]. As ensinanzas relixiosas xudías condenan a homosexualidade masculina mais non din nada da feminina (Wikipedia s.d.).

Isto é, con certeza, sintomático do facto de as lesbianas, como as mulleres en xeral, seren simplemente ignoradas ou non consideradas abondo significativas para seren dignas de mención en moitos niveis. Así, mediante a escrita, son simplemente eliminadas da sociedade e, como consecuencia, tamén da lingua en que a sociedade se exprime. Porén, en contra do que se poida supor, non se recoñecer a existencia dun grupo marxinal da sociedade torna este grupo invisíbel e impotente en vez de protexelo implicitamente do ataque directo, da crítica e da represión: "Nun mundo en que a lingua e os nomes son o poder, o silencio é opresivo, é violencia" (Rich 1979: 204).

Neste artigo exploraremos e analizaremos os modos en que estas visións da sexualidade humana culturalmente condicionadas, androcéntricas e/ou hetero- 
normativas poden ser identificadas nin só en leis abertamente discriminatorias e anticuadas, mais tamén na tradución como proceso que envolve a lectura e a (re)interpretación do papel de xénero e das expectativas relativas á "normatividade" sexual por parte do/a tradutor/a. Aínda que o modo en que as mulleres en xeral e as lesbianas en particular son tratadas e manipuladas mediante o proceso de tradución ten suficiente interese en si, tamén é útil para ilustrar a máis ampla cuestión de como calquera grupo social "marxinal", isto é, non androdominante, pode ser (mal)tratado durante procesos sensíbeis á cultura e á ideoloxía, como é a tradución.

A pesar do interese que tales focaxes teñen per se e tamén polas súas ulteriores implicacións para o estudo das escollas de tradución motivadas ideoloxicamente, estas preocupacións minoritarias teñen sido infelizmente rexeitadas por seren demasiado marxinais para teren importancia para quen practica a tradución ou para quen a estuda. Este argumento pode ser contestado de dúas maneiras: en primeiro lugar, o facto de un grupo social particular ser numericamente minoritario non dá en si dereito a ninguén a eliminar a súa existencia da tradución varréndoo cunha pena (in)conscientemente carregada de preconceptos, nunha especie de euxenía literaria practicada por un capricho do/a tradutor/a; en segundo lugar, están a ser producidas moitas obras literarias, en particular nos países de fala inglesa, embora non exclusivamente, con autoras destacadas como Sarah Waters e Jeanette Winterson, que conseguiron aparecer na BBC no horario de máxima audiencia ${ }^{2}$. Ignorar estas contribucións "marxinais" á literatura e ao pensamento antigo e moderno é un prexuízo que empobrece o canon europeo occidental frecuente e incorrectamente chamado "Literatura Universal". Non podemos senón perguntarnos que sería da poesía grega clásica sen Safo de Lesbos.

É evidente que se debe exixir do/a tradutor/a unha certa sensibilidade cando tratar con textos cunha clara carga homosexual, como os casos acima descritos. Porén, o problema real non reside tanto na tradución de literatura aberta e declaradamente LGBT (lesbigay e trans), canto na redacción ambiguamente neutral que Bodine (1975: 131) chama "de sexo oculto", en que o xénero das personaxes está reflectido na gramática de forma pouco clara ou ambigua por calquera razón. Exemplos deste tipo de redacción son máis frecuentes do esperado, e poden encontrarse nas obras de Jeanette Winterson en inglés, de Carme Riera en catalán (1989) ou de Anne Garréta en francés (1999) A diferenza do caso antes referido de literatura

2 Oranges are Not the Only Fruit, de Jeanette Winterson (1985, Pandora Press), gañadora do Premio Whitbread, foi adaptada como serie de televisión pola BBC en 1990. Tipping the Velvet, de Sarah Waters (1999, Virago) tamén foi adaptada como unha miniserie de tres capítulos emitida aos domingos no horario de máxima audiencia e reposta pola BBC en 2003. Existe unha listaxe detallada das personaxes homosexuais que apareceron na BBC desde 1979 até hoxe no artigo dispoñíbel en <http://www.bbc.co.uk/drama/tipping/article_1.shtml> (en inglés). 
explicitamente LGBT, en que as/os tradutoras/es deberían estar atentos aos problemas que se lles presentan, neste último caso, os preconceptos e as expectativas referentes aos estereotipos sexuais, aos papeis sociais de xénero e á sexualidade poden, de forma inconsciente ou non tan inconsciente, sobreporse ao que debería ser traducido.

\section{O estudo}

A expurgación androcéntrica que Howard M. Parshley levou a cabo cando traduciu $O$ Segundo Sexo de Simone de Beauvoir deberá ser lembrada como un dos exemplos máis notorios de como un/ha tradutor/a pode chegar a manipular o pensamento orixinal dun autor para facelo coincidir coas súas propias necesidades ideolóxicas:

máis de $10 \%$ do material da edición orixinal francesa, incluíndo a metade dun capítulo e os nomes de setenta e oito mulleres da historia, foi eliminado. Esas supresións non sinaladas danan gravemente a integridade da análise que de Beauvoir fai de temas tan importantes como os movementos sufraxistas do século XIX nos Estados Unidos e na Europa, ou o desenvolvemento do feminismo socialista na Franza (Simons 1983).

Podemos encontrar numerosos casos similares, como os citados por Wandruszka (1969: 172 - as anotacións son nosas):

"Same cook I suppose, Maxim" (tirado de Rebecca, de Daphne de Maurier)

Francés: la même cuisinière

(Q)

Italiano: lo stesso cuoco (

Español: el mismo cocinero $\quad\left(0^{7}\right)$

Portugués: a mesma cozinheira (\$)

Alemán: die selbe Köchin (†)

"One of my secretaries was remarking only this morning how well and young I am looking"

Francés: Un de mes secrétaires $\quad .\left(0^{7}\right)$

Italiano: Uno dei miei segretari $\quad\left(0^{7}\right)$

Español: Una de mis secretarias (\$)

Portugués: Uma das minhas secretárias (\$)

O que estes exemplos mostran con clareza é que cando se traducen termos epicenos dunha lingua como o inglés, que xeralmente non marca o xénero gramatical, para linguas como o francés, o español, o italiano, etc., nas cales a expresión do 
xénero gramatical por medio de marcas morfolóxicas é obrigatoria, o/a tradutor/a se ve obrigado/a a atribuír un xénero a termos que doutro xeito non estarían marcados. A superposición entre o xénero gramatical e o "natural" tórnase clara cando é aplicada a ítems lexicais como os nomes das profesións e outros.

$\mathrm{Na}$ práctica, por tanto, é decisión do/a tradutor/a individual a determinación da identidade xenérica dos referentes e é xusto supor que isto é feito, polo menos na maioría dos casos, baseándose en expectativas condicionadas culturalmente e referidas á asignación de papeis sociais de xénero nun contexto sociocultural determinado. Así, do mesmo modo que a lingua, como construto e convención social, non pode ser neutral porque evolúe, se desenvolve e existe dentro dun cadro sociocultural predominantemente androcéntrico e heteronormativo, tampouco a tradución é neutral:

$\mathrm{O}$ "Eu" tradutora non é neutral e nunca o foi [...]. Do mesmo xeito que os intérpretes da Biblia, as/os tradutoras/es poden supor unha ameaza para a orde estabelecida. Así, na historia, a tradución ten cruzado a espada co poder. A tradución como práctica feminista faino por definición (de LotbinièreHarwood 1991: 98).

Como suxire a observación de Lotbinière-Harwood citada acima, toda tentativa de subverter o uso lingüístico estabelecido como reflexo do statu quo dominante na sociedade é interpretada como un desafío directo aos discursos sociais dominantes e é vista como unha ameaza á autoridade. Isto explica a trazos largos a continuada resistencia á innovación lingüística destinada a revelar e debilitar os estereotipos sociais fosilizados no uso lingüístico aceptado e camuflados como "normalidade" neutral, por exemplo os masculinos pseudoxenéricos. Esta análise provén de facto da opinión exprimida por autores como Smith (2002: 53), que afirma textualmente sentirse "atacado" por tales propostas cando escribe que moitos "aspectos da campaña en favor da corrección política levan a marca do autoritarismo, mais esta é inofensiva se non vai acompañada de censura" (Smith 2002: $56)$.

Este tratamento manipulador e abusivo que o uso lingüístico dá ás mulleres baseándose nas expectativas do papel social de xénero esténdese na tradución até chegar a cumprir as expectativas a respecto do que se percibe como unha orientación sexual "normal". Como se ve no seguinte exemplo citado en Nissen (2002: 34), fica claro que a escolla do feminino alemán para traducir o epiceno inglés "fair friend" 'cara amiga ou caro amigo' está motivada por expectativas de sexualidade segundo as cales, se o autor dunha frase tan afectuosa é un home, só é "razoábel" que o referente sexa unha muller dentro dun cadro ideolóxico referencial no cal a heteronormatividade é o único padrón de comportamento aceptábel. 
"To me, fair friend, you never can be old" Shakespeare (Soneto 104) Für mich, Geliebte... $\quad\left(\sigma^{7}\right) \quad(1867$, traducido por Karl Simrock $)$ Für mich, Geliebter... (ㅇ) (1873, traducido por Friedrich Bodenstedt)

Sen dúbida, o exemplo máis notábel dunha tradución como traizón énos fornecido polo xeito en que os poemas de Safo foron intencionalmente manipulados para heterosexualizar a propia poeta, tornando así a súa poesía menos ameazante para a sociedade, isto é, a literatura de calidade non pode ser de, para ou sobre alguén que se encontre fóra da orde estabelecida e, sen dúbida, non pode falar sobre as lesbianas:

Perante a súa poesía erótica, faise difícil crer que os expertos continúen a defender que Safo non era lesbiana no sentido moderno da palabra [...]. Os críticos (fundamentalmente homes), escandalizados ante a idea de que as mulleres poidan manter relacións homosexuais, tentaron negar o lesbianismo de Safo. Entre as súas prácticas inclúese a tradución deliberadamente inadecuada de palabras que indican que a amada é unha muller, así como o estabelecemento dun contexto heterosexual en poemas que describen o desexo lésbico [...]. Esas traducións son un modo insidioso (embora non intencional) de heterosexualizar Safo (Gbltq on-line 2002-2005).

Abondará proporcionar un breve fragmento, xunto con algunhas traducións, dun dos poemas de amor de Safo escollido ao acaso para ilustrar o alcance da manipulación levada a termo por algúns dos tradutores implicados ${ }^{3}$ :

\section{Orixinal grego ${ }^{4}$}

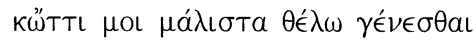

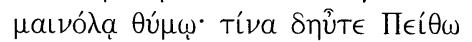

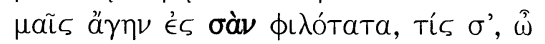

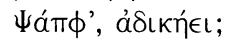

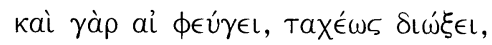

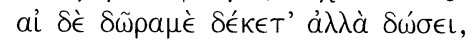

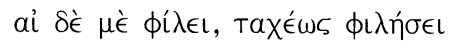

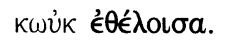

\section{Tradución "homosexual"}

What I in my mad heart most desire to see. 'What Beauty now wouldst thou draw to love thee? Who wrongs thee, Sappho?

For even if she flies she shall soon follow, and if she rejects gifts shall yet give, and if she loves not shall soon love, however loth.' (H.T. Wharton 1895)

3 Tirado de The Divine Sappho <http://classicpersuasion.org/pw/sappho/sape01u.htm> (en inglés).

4 Versión galega dos tradutores a partir do orixinal: [Preguntaches] o que o meu louco corazón máis desexaba: / "Quen de novo hei convencer / Para levarte ao seu amor? / Quen, o Safo, te maltrata? // Pois se hoxe foxe, perseguirá; I non quer presentes, mais ha de dar; / e se non ama, logo amará / queira ela ou non". 
Comparemos a tradución homosexual acima citada co que só pode ser descrito como algúns dos exemplos máis flagrantes de autocensura dirixida a ocultar toda realidade "indecente" aos destinatarios da tradución":

What frenzy in my bosom raged, And by what cure to be assuaged? What gentle youth I would allure, Whom in my artful toils secure?

Who does thy tender heart subdue, Tell me, my Sappho, tell me who?

Though now he shuns thy longing arms, He soon shall court thy slighted charms; Though now thy offerings he despise, He soon to thee shall sacrifice; Though now he freeze, he soon shall burn, And be thy victim in his turn.

(Ambrose Philips 1711)
What end my frenzied thoughts pursue For what loved youth I spread anew My amorous nets- 'Who, Sappho, who 'Hath done thee wrong?

What though he fly, he'll soon return'Still press thy gifts, though now he spurn; 'Heed not his coldness-soon he'll burn, 'E'en though thou chide.'

(John Herman Merivale 1833)

\section{A tradución como ferramenta para a investigación}

En xeral, costúmase ignorar que as/os tradutoras/es non son só (re)escritoras/es, mais tamén, e talvez principalmente, lectoras/es dos textos que traducen. Como tales, poden ser utilizados como suxeitos experimentais que representan o arquetipo do público lector destinatario para comprobar empiricamente como as persoas reaxen inconscientemente ante o que len e como o procesan.

A introdución de exercicios baseados na tradución como ferramenta experimental ten o potencial necesario para mellorar as probas destinadas a revelar as percepcións e expectativas subxacentes sobre a sexualidade e o papel social de xénero. A posíbel distancia semántica entre a "connotación" e a "denotación" dun termo pode facerse explícita mediante a realización de probas baseadas na tradución coidadosamente deseñadas. A connotación dunha palabra correspóndese coa súa "intensión" vista como o conxunto de asociacións que unha palabra provoca na mente de quen a emite e de quen a recibe, por oposición ás características denotativas da mesma palabra, a súa "extensión", que remiten directamente para os referentes que esa palabra describe.

5 Obsérvese que a data da tradución de Wharton é semicontemporánea á de Merivale, isto é, non se trata dunha revisión e reescrita do texto nun período histórico diferente. 
É útil relacionarse os conceptos semánticos máis largos de connotación/intensión e de denotación/extensión con outros conceptos máis específicos chamados "xénero oculto" ou "social" co obxectivo específico de relacionar o uso lingüístico e as súas percepcións e expectativas dentro dun contexto andro- e/ou heterocéntrico (véxase Braun 2001: 61):

O xénero social é unha categoría que se refire "á dicotomía imposta pola sociedade entre os papeis sociais e os trazos de carácter masculinos e femininos" (Kramarae / Treichler 1985: 173). O xénero social é especificado para os substantivos persoais cando as palabras a eles asociadas se comportan dun xeito que non pode ser deducido nin do xénero gramatical nin do léxico. Un exemplo do uso do xénero social en inglés é o facto de que moitos termos referidos a profesións de alta categoría como lawyer 'advogada ou advogado', surgeon 'cirurxiá ou cirurxián' ou scientist 'cientista' reciben o pronome masculino he 'el' en contextos en que o xénero do referente é descoñecido ou irrelevente. Por outro lado, as denominacións de profesións de baixa categoría como secretary 'secretaria ou secretario', nurse 'enfermeira ou enfermeiro' ou schoolteacher 'mestra ou mestre' son frecuentemente acompañadas do pronome anafórico she 'ela'. Mais aínda no caso de substantivos persoais xerais como pedestrian 'viandante', consumer 'consumidor ou consumidora' ou pacient 'paciente', a práctica tradicional prescribe a escolla de he en contextos neutrais (Hellinger / Bußmann 2001: 10-11).

Un sinxelo exemplo desta división pode ser visto na semántica aberta (denotativa) en oposición á cuberta (connotativa) implícita en termos como nurse e doctor 'doutor ou doutora' que, a pesar de seren epicenos en inglés, o primeiro tende a ser identificado como feminino en canto o segundo tende a ser interpretado como masculino baseándose en expectativas do papel social de xénero, como mostra o uso típico dos pronomes anafóricos ${ }^{6}$, por exemplo "When the doctor comes, tell him that..." "cando o doutor chegar, dille (a el) que...' en oposición a "When the nurse comes, tell her that..." 'cando a enfermeira chegar, dille (a ela) que...'

No nivel experimental, as probas empíricas das expectativas do papel social de xénero subxacentes á hora de interpretar termos gramaticalmente epicenos presentadas para o finés en Engelberg (2002: 122) demostraron claramente que unha aparente neutralidade pode esconder preconceptos condicionados pola sociedade: "Os referentes do termo superordinado ihminen 'ser humano' e de moitos dos seus

6 Tales usos son comúns, como mostra o exemplo dun manual de turco para principiantes escrito en francés: 'Remarquez l'absence de féminin et de masculin: öğrenciyim: je suis étudiant(e). Türk: Il est turc ou Elle est turque' ['Obsérvese a ausencia de feminino e masculino: ögrenciyim: eu son estudante, Türk: El é turco ou Ela é turca']. A pesar de que o masculino francés é empregue en todo o texto para traducir a maior parte dos (pseudo)epicenos turcos, como ingénieur 'enxeñeiro', étudiant 'estudante $(m)$ ', médecin 'doutor', enseignant 'mestre' ou acteur 'actor', hemșire está especificamente marcado como feminino, infirmière 'enfermeira' (Colin / Koşar 1997: 6-10). 
homónimos morfoloxicamente epicenos son máis frecuentemente percibidos como masculinos do que como femininos".

Os estudos elaborados por Braun (2001: 287) sobre unha lingua diferente, o turco, que non marca o xénero gramatical e está ligada a unha sociedade predominantemente androcéntrica, corroboran estes resultados:

a semántica dos termos turcos utilizados para referirse ás persoas está determinada por factores socioculturais máis que pola ausencia de xénero gramatical [...]. Este sistema de crenzas sobre o xénero produciría preconceptos ou expectativas de xénero que se manteñen ocultas baixo a neutralidade gramatical da estrutura lingüística.

Neste experimento concreto, os suxeitos foron examinados para comprobar en que medida a ausencia de xénero gramatical na denotación de termos referidos a profesións como kuyumcu 'ourives' memur 'empregada ou empregado da banca', temizliçi 'limpador ou limpadora', sekreter 'secretaria ou secretario' e outros corresponde na mente dos e das falantes con connotacións gramaticalmente epicenas cando se fai referencia a persoas tipicamente asociadas con eses termos.

Este exame completouse coa introdución do que Braun chamou 'dominios' de xénero, isto é, 'dominio masculino', 'dominio feminino' e 'dominio neutro', referidos a actividades ou profesións atribuídas arquetipicamente a un ou a outro xénero (ou a ningún). Este concepto de 'dominios' corresponde vagamente co que chamaremos aquí 'cadros semánticos', unha útil adición ás metodoloxías experimentais á hora de deseñar probas dirixidas a extraer dos suxeitos respostas que revelen calquera tipo de preconceptos ou expectativas do papel social de xénero ou relativas á sexualidade subxacentes, e que estean asociadas con calquera ítem lexical.

En vez do significado técnico e restrito do termo asociado tipicamente ás obras de Minsky (1975) e Fillmore (1976) que tratan da intelixencia artificial e do procesamento automático da linguaxe, usaremos aquí o termo 'cadro semántico' nun sentido moito máis lato para nos referirmos ao contexto lingüístico ou pragmático en que unha determinada elocución é emitida e á luz do cal son interpretados os diferentes elementos lexicais e morfolóxicos que a comprenden. Os contextos ou 'cadros' deste tipo poden ser elaborados coidadosamente para extraeren respostas destinadas a resaltar toda posíbel expectativa do papel social de xénero ou relativa á sexualidade asociada a termos gramaticalmente epicenos. Noutras palabras, os cadros semánticos sensíbeis á cultura e á sociedade poden responder pola fenda existente entre as denotacións semánticas por unha parte e as connotacións pola outra. Por exemplo, os diferentes cadros semánticos baseados en expectativas de comportamento relativas ao papel social de xénero nas dúas oracións que seguen poderían ser responsábeis da asignación de xénero masculino e feminino respectivamente ao termo non marcado cousin 'prima ou primo'. 
My cousin was playing with a gun, que sería traducido para galego como ' $\mathrm{O}$ meu primo estaba a xogar cunha pistola.'

My cousin was playing with a doll, que sería traducido para galego como 'A miña prima estaba a xogar cunha boneca.'

Experimentos como os realizados por Braun (2001) e Engelberg (2002) para o turco e o finés repectivamente poden ser mellorados pola introdución da tradución como ferramenta experimental, como no caso de Frank / Hoffmann / Strobel (2004), que analizaron a precisión das traducións automáticas a respecto das variábeis de xénero. Aquí, no entanto, propomos dar a volta a esta situación e usarmos a tradución como ferramenta metodolóxica para medirmos e avaliarmos as percepcións do papel social de xénero e as expectativas relativas á sexualidade que subxacen na mente dos utentes da lingua e das tradutoras e dos tradutores. Os pares de linguas estudados poden ser escollidos especificamente de xeito que revelen connotacións semánticas carregadas de preconceptos que se oculten baixo a superficie aparentemente neutral de termos epicenos.

Por exemplo, recentemente foi levada a termo unha proba-piloto de que se informa en Baxter (2005) e que pretendía demostrar como as probas baseadas na tradución poden ser utilizadas para medir posíbeis connotacións subxacentes influídas polo xénero e asociadas a certos termos por parte das falantes/tradutoras. Nesta proba pedíase aos suxeitos para traduciren oracións simples de inglés para galego. As frases escollidas foran deseñadas para obrigaren de xeito implícito os suxeitos a faceren escollas léxicas e morfolóxicas en que o xénero estivese marcado gramaticalmente de forma explícita e que estivesen motivadas por expectativas preconcibidas do papel social de xénero ao traduciren termos epicenos do inglés para galego, lingua en que a marca de xénero na morfoloxía é obrigatoria, p. ex. 'As the couple had had no children, the judge decided that the inheritance would automatically revert to their next of kin' 'Como o casal non tivera descendencia, a xuíza ou o xuíz decidiu que a herdanza pasaría automaticamente ao parente máis próximo.' Nótese que, neste caso concreto, un uso incorrecto do masculino pseudoxenérico fillos en galego para traducir o epiceno inglés children constituiría de facto un grave erro de tradución, por ser esta ambigua e por ter implicacións legais, xa que se podería interpretar que o casal non tiña fillos varóns mais podería ter tido unha ou varias fillas que, porén, non terían dereito á herdanza por causa do seu sexo (como, por exemplo, no caso da monarquía española).

Exemplos como este poden ser reformulados para comprobar os posíbeis preconceptos heterosexistas implícitos no comportamento dos tradutores e das tradutoras, p. ex., 'The secretary kissed the man' > 'A secretaria/O secretario beixou o home' ou tamén o caso contrario, traducindo de linguas pro-drop, isto é, con tendencia a non explicitar o suxeito, como o galego, para unha lingua en que os pro- 
nomes de suxeito son obrigatorios e teñen marca de xénero, como o inglés, p. ex. '(Ø) Beixouna' > '(She/He) kissed her'.

Recentemente realizamos un breve experimento para confirmarmos a nosa sospeita a respecto dos preconceptos heterosexistas nos tradutores e nas tradutoras, pedindo a un grupo de aproximadamente vinte estudantes do último ano de tradución para traduciren a seguinte oración de galego para inglés: 'Despois dunha noite de paixón, levantouse, beixouna e marchou traballar deixándoa a esperar o seu marido'. O galego é unha lingua pro-drop e, por tanto, o sexo dunha das personaxes da oración de proba non é especificado abertamente, en canto a sintaxe inglesa exixe un pronome de suxeito obrigatorio. A terceira persoa de singular dos verbos obriga o/a tradutor/a a escoller entre o pronome persoal masculino he ou o feminino she. A pesar de que este tema fora debatido recentemente na aula, algúns dos suxeitos do experimento aínda presupuñan 'de xeito automático' que se unha das personaxes era explicitamente unha muller, a outra debería ser 'loxicamente' un home. Cando se lles perguntou, non vían nada 'estraño' na oración que a fixese merecedora dunha análise máis demorada.

O que isto demostra con clareza é que as/os tradutoras/es costuman proxectar nos seus textos-albo as súas expectativas sobre a sociedade e o comportamento humanos baseadas no discurso dominante recibido, isto é, as relacións heterosexuais son a norma e as relacións maritais heterosexuais exclúen as relacións homosexuais extramaritais, estea isto ou non implícito no texto-fonte. Sería posíbel defender os suxeitos do experimento argumentando que as presuposicións das tradutoras e dos tradutores son 'xustificadas' por estaren baseadas no seu coñecemento das normas sociais dominantes. É, no entanto, dubidoso que alguén poida ter o dereito a silenciar calquera grupo social co único argumento de que constitúe unha minoría nas sociedades en que as/os tradutoras/es viven ou coas cales están familiarizados.

Mais estes exemplos non aparecen só en circunstancias experimentais especialmente preparadas (mesmo alguén podería dicir 'forzadas'), como se demostra nos seguintes exemplos tirados de obras de ficción modernas:

Jamie had had a mad crush on Lauren, her friend since college, for years. It had become an inside joke between Jane and Madison. Part of the joke was that Lauren had no clue (Casavent 2003: 7).

'Okay! You win!' Anna eased herself down from the window.

'You're such a fucking smart-arse sometimes.'

Cass slapped her on the bum. 'Smart-arsed enough to get my girlfriend pregnant!'

'Very funny!'Anna sat on the loo.'And what about next-door?' (Boulter 2002: 2). 
When a respected professor's wife drives to her death in an icy river, an illicit relationship between a student and his teacher threatens to come to light (Rice 2001: Contracapa)

E aínda que sexa certo que o xénero que corresponde ás personaxes en cuestión sería corrixido por calquera tradutor/a minimamente atento/a a medida que aṽanzase a historia e a sexualidade das personaxes se tornase clara, isto non implica necesariamente que ese tradutor ou esa tradutora fose voltar ao principio para procurar e corrixir os erros que puidese ter cometido.

\section{Conclusións}

Tense dito que a lingua, como construto social, é inevitabelmente androcéntrica posto que a sociedade tamén o é, o que levou á criación de linguas femininas especiais como o láadan e o non tan ficticio nửshū (véxase Hader Elgin 1988; Ager 1998-2004). Tanto as versións moderadas da hipótese do determinismo lingüístico canto as focaxes contemporáneas dos Queer Studies que usan o modelo de análise dos actos de fala performativos mostran que a realidade e o modo en que as e os falantes a perciben, se relacionan con ela e axen sobre ela están, cando menos en parte, influídos pola lingua que usan e, especialmente, pola maneira en que a usan.

A tradución, como fenómeno intimamente ligado á lingua e aos intercambios sociais e interculturais, tamén reflicte as percepcións socialmente estruturadas a respecto das connotacións ideolóxicas implícitas relacionadas con cuestións e fenómenos tan sensíbeis e arraigados na cultura como son os papeis sociais de xénero e as expectativas sobre a sexualidade humana.

A pesar de que a aceptación na opinión pública xeral de certas partes do discurso feminista abriu as portas para o crecemento do interese polo modo en que as mulleres son consideradas e representadas na sociedade, e tamén por como son tratadas na tradución, o estudo doutros grupos sociais marxinalizados como os LGBT en xeral e as lesbianas en particular recibiu moita menos atención nos círculos académicos dedicados aos Estudos de Tradución e disciplinas afíns.

A tradución pode ser vista nin só como obxecto de análise, mais tamén como unha útil ferramenta metodolóxica para descubrir preconceptos ideolóxicos semánticos asociados a certos termos e baseados nas expectativas do papel social de xénero ou relacionadas coa sexualidade. Os exercicios baseados na tradución, cando usados con xuízo, poden servir como ferramenta empírica para descobrir as enraizadas fendas existentes entre a posíbel denotación e as connotacións de termos socioculturais conflituosos. 
Os resultados de tales experimentos poden facernos compreender mellor e dun xeito máis obxectivo a maneira en que as e os falantes utilizan a lingua e se relacionan con ela e, a través dela, coa sociedade en varios niveis semánticos diferentes. No nivel pedagóxico, estas probas poden ser utilizadas para aumentar a consciencia das tradutoras e dos tradutores a respecto das súas propias expectativas socioculturais para corrixilas, evitando así pasalas ao público destinatario inconscientemente. Un proceso semellante resultaría en traducións máis 'fieis' aos orixinais, comunicando así ao público receptor o que o autor orixinal tencionaba e non o que o/a propio/a tradutor/a decidira (erradamente) que o autor debería ter tencionado á luz da súa propia cosmovisión ideoloxizada.

Tales preocupacións polo uso lingüístico, frecuentemente consideradas "politicamente correctas", non implican de facto, como se costuma argüír, unha politización da tradución no senso dunha aplicación de determinadas inclinacións ideolóxicas ao que está escrito, mais a súa desideoloxización, xa que se tenta eliminar toda connotación carregada de preconceptos ideolóxicos, sexan machistas, androcéntricos e/ou heterosexistas ou non. É un erro tentador, mais tamén perigoso, confundir as relacións de poder representadas polo statu quo e reflectidas na lingua e na tradución coa neutralidade obxectiva, a cal, en certos casos, só pode ser garantida pola intervención directa, desde o uso obrigatorio e apoiado oficialmente da chamada "linguaxe politicamente correcta" até o estabelecemento e a implementación da acción afirmativa.

Para concluírmos, estudos como os citados neste artigo son un exemplo excelente do potencial dos Estudos de Tradución como unha disciplina verdadeiramente transversal dentro do vasto campo das Ciencias Sociais, mantendo en grande medi$\mathrm{da}$ as focaxes multidisciplinares necesarias para se comprender un mundo cada vez máis complexo. Aínda máis, alén do interese que teñen en si a análise e a avaliación do xeito en que os grupos sociais marxinalizados son tratados nas traducións, este tipo de estudos pode lanzar luz sobre o modo en que as/os tradutor/ases caen na tentación, consciente ou non, de sucumbir ante as súas propias expectativas condicionadas pola súa cultura a respecto de todo tipo de cuestións social e culturalmente conflituosas. Noutras palabras, se un/ha tradutor/a pode eliminar as lesbianas dos seus textos, que probabilidade existe de que introduza no texto-albo outras mudanzas motivadas pola súa ideoloxía?

Estudos deste tipo poden ser un medio útil para incrementar a preocupación polo modo en que as/os tradutoras/es proxectan nos textos-albo as súas propias cosmovisións e expectativas construídas cultural e ideoloxicamente sen se decataren, transmitíndoas así ao público lector destinatario. Deste xeito, estes estudos sobre o xénero e a sexualidade serían unha valiosa adición a calquera currículo académico relacionado co ensino da tradución e ao mesmo tempo fortalecerían os esforzos continuados para introducir na sociedade a preocupación polas cuestións de xénero. 


\section{Referencias bibliográficas}

Ager, S. (1998-2004): "Nushu", en Ager, S, Omniglot, <http://www.omniglot.com/writing/nushu.htm>.

Baxter, R.N. (2005): "On the need for non-sexist language in translation", en Thao Le (2005), Language, Society and Culture, $15<\mathrm{http}: / /$ www.educ.utas.edu.au/ users/tle/JOURNAL/ARTICLES/2005/15-1.htm>

Bodine, A. (1975): "Androcentrism in prescriptive grammar: singular 'they', sex-indefinite 'he', and 'he or she'", Language in Society, 4 (2): 129-146.

Boulter, A. (2002): Around the Houses (London: Serpent's Tail).

Braun, F. (2001): "The Communication of Gender in Turkish", en Hellinger, M / Bußmann, H. (eds.) (2001), Gender across languages. Vol. 1: 283-310 (Amsterdam / Filadelfia: John Benjamins).

Casavent, J. (2003): Twist of Fate (Nederland:Yellow Rose Books).

Colin, S. / Koşar, S. (1997): Le turc tout de suite (París: Pocket-Langues pour tous).

Dworkin, A. (1994): "The Unremembered: Searching for Women at the Holocaust Memorial Museum”, Ms. Magazine, Vol. V, 4: 5258.

Engelberg, M. (2002): "The Communication of Gender in Finnish", en Hellinger, M. I Bußmann, H. (eds.) (2002), Gender across languages. Vol. 2: 109-132 (Amsterdam / Filadelfia: John Benjamins).

European Commission (1995-2005): “Gender Mainstreaming", en Europa <http://europa.eu.int/comm/employment_social/equ_opp/gms_en.html>

Even-Zohar, I. (1990): "Polysystem Studies", International Journal For Theory and Analysis of Literature and Communication. Vol. 11, 1, http://www.ifrance.com/itamarez/ps/polysystem.html

Fillmore, C. J. (1976): "Frame semantics and the nature of language", Annals of the New York Academy of Sciences: Conference on the Origin and Development of Language and Speech, 280: 20-32.

von Flotow, L. (1997): Translation and Gender. Translating in the 'Era of Feminism' (Manchester / Ottawa: St. Jerome Publishing e University of Ottawa Press).

Frank, A. / Hoffmann, C. I Strobel, M. (2004): "Gender Issues in Machine Translation", en International Symposium Gender Perspectives Increasing Diversity for Information Society Technology (GIST) (Bremen 2003) (Heidelberg: Lingenio).

Garréta, A. F. (1999): La Décomposition (París: Grasset et Fasquelle).

Haden Elgin, S. (1988): A First Dictionary and Grammar of Laadan (Society for the Furtherance and Study of Fantasy and Science Fiction, Inc).

Hellinger, M. / Bußmann, H. (2001): "Gender across language. The Linguistic Representation of Women and Men”, en Hellinger, M. / Bußmann, H. (eds.) 
(2001), Gender across languages, Vol. 1: 1-25 (Amsterdam / Filadelfia: John Benjamins).

de Lotbinière-Harwood, S. (1991): Re-belle et infidèle. La traduction comme pratique de réécriture au féminin / The Body Bilingual. Translation as rewriting in the feminine (Ontario / Quebec: Woman's Press e Éditions du remue-ménage).

Martín Ruano, M.R. (2003): El (des)orden en los discursos: la traducción de lo políticamente correcto. Tese de doutoramento en formato dixital (Granada: Universidad de Granada)

Minsky, M. (1975): “A framework for representing knowledge”, en The Psychology of Computer Vision: 211-277 (Nova Iorque: McGraw-Hill).

Nissen, U.K. (1994): “Is cook ‘der Koch' oder ‘die Köchin'? Problems of (social) gender in translation", Hermes. Zeitschrift für Klassische Philologie, 12: 51-63.

Nissen, Uwe Kjær (2002): “Aspects of Translating Gender”, en Hentschel, E. (ed.) (2002), Sprache und Geschlecht/Language and Gender, Linguistik on-line, 11, 2/02 <http://www.linguistik-online.de/11_02/nissen.pdf>.

Riera, C. (1989): Te deix, amor, la mar com a penyora (Barcelona: Laia).

Rice, C. (2001): Snow Garden (Nova Iorque: Miramax Books).

Rich, A. (1979): On Lies, Secrets and Silence: Selected Prose: 1966-78 (Nova Iorque: Norton).

Sedgwick, E.K. (1995): Performativity and Performance (Essays from the English Institute) (Nova Iorque e Londres: Routledge).

Simons, M. A. (1983): “The Silencing of Simone de Beauvoir: Guess What's Missing from the Second Sex", Women's Studies International Forum, 6, $\mathrm{n}^{\circ} 5$.

Smith, N. (2002): Language, Bananas \& Bonobos. Linguistic Problems, Puzzles and Polemics (Oxford: Blackwell).

Spender, D. (1985): Man made language (London: Routledge \& Kegan Paul).

Toury, G. (1981): "Translated Literature - System, Norm, Performance: Toward a TTOriented Approach to Literary Translation", en Poetics Today, II, 4 (Tel Aviv: The Porter Institute for Poetics and Semiotics).

VV.AA. (2006): "Lesbian”, en Wikipedia, The Free Encyclopedia. <http://en.wikipedia.org/w/index.php?title=Lesbian\&oldid=40553903>

VV.AA. (2006): "Sappho", en An encyclopedia of gay, lesbian, bisexual, transgender and queer culture (Chicago: Gbltq, Inc.) <http://www.glbtq.com/literature/sappho, 3.html>

Wandruszka, M. (1969): Sprachen: vergleichbar und unvergleichbar (Munique: R. Piper).

Whorf, B. (1964): Language, Thought, and Reality: Selected Writings of Benjamin Lee Whorf (Cambridge-Boston: MIT Press) 